\title{
THE ROLE OF TRANSALPINE FREIGHT TRANSPORT \\ IN A COMMON EUROPEAN MARKET: \\ ANALYSES AND EMPIRICAL APPLICATIONS
}

\author{
Aura Reggiani ${ }^{*}$, Peter Nijkamp ${ }^{* *}$, Simona Bolis ${ }^{* * *}$ \\ * Department of Economics, Università di Bologna, Piazza Scaravilli, 2 \\ 40126 Bologna, Italy - e-mail: reggiani@economia.unibo.it \\ ** Department of Regional Economics, Free University, De Boelelaan 1105 \\ 1081 HV - Amsterdam, The Netherlands - e-mail: pnijkamp@econ.vu.nl \\ *** Department of Economics, University of Lugano, Via Ospedale 13 \\ 6900 Lugano, Switzerland - e-mail: boliss@eco.usi.ti-edu.ch
}

\begin{abstract}
The paper focuses on the Trans Alpine Freight Transport systems in the light of the future integration of single national transport systems into the European transport network. The environmental, social and institutional peculiarities of this 'region' have favoured - in the past - the development of strong nationally-oriented policies, which are largely in contrast with the goals promoted by the European Union. The present analysis aims to highlight opportunities and limits inherent in the implementation of various new network projects, with a particular view on the planned changes of the Alpine transport system. In this framework, a concise description of the existing and 'planned' situation will be offered.

In addition, some new forecasting analyses for road transport will be offered on the basis of environmentally-based transport scenarios. In particular, given the high dimension of our data-base on European transport flows, two different approaches will be compared, viz. the logit model and the neural network model. Logit models are well-known in the literature; however, applications of logit analysis to large samples are more rare. Neural networks are nowadays receiving a considerable attention as a new approach that is able to capture major patterns of spatial flows, on the basis of fuzzy and incomplete information. The tentative results of both approaches in this context may then be used as a benchmark for judging the results of other transport flow models and offer also a more 'flexible' range of results to policy actors. Furthermore, our study will present the assessment of transEuropean freight flows based on interesting future scenarios related to further congestion and the introduction of eco-taxes on transport in Europe.
\end{abstract}




\section{EUROPEAN TRANSPORT IN QUESTION}

Integrated common market policy is at the heart of current European Union objectives. A free exchange of persons, commodities and capital has far reaching implications for intraEuropean trade and transport. Recent policy documents show that transport in Europe may be looked at from three partly complementary, partly competing policy angles: the need for competitive efficiency, the need for geographical accessibility for all regions in Europe, and the need for an environmentally sustainable development. These three broad policy objectives will now be discussed in more detail.

Competitive efficiency is in the centre of current European transport policy, where massive investments in Trans European Networks and in missing links serve to support the goal of economic integration. But also at local, metropolitan and regional scales formidable investment efforts are foreseen in order for main players to survive in a competitive world market based on global networks. Efficiently operating transport networks in the former segmented European space-economy are critical success factors for the competitive edge of Europe.

There is in the second place a major concern on geographical accessibility of less central regions in Europe. The low density of transport needs in many rural and peripheral areas has always been a permanent source of concern of public authorities, from the viewpoint of both the service quality offered by public transport operators and the objectives set for regional development. A look at the historical development of European infrastructure networks (road, rail, air, waterways) makes immediately clear that the most important links were first constructed between major centres of economic activity. The connections with rural and peripheral areas were in all cases delayed. Without granting a transport operator a natural monopoly, such connections would perhaps never have been realized. This is a clear case where efficiency motives and equity motives are in conflict with one another. In the emerging European welfare states however, the rights of the rural and peripheral areas have been recognized as legitimate claims, even though the economic feasibility of such 'extracentral' connections was often clearly negative. But the equity argument - often reinforced by the 'generative' argument (i.e., an infrastructure - once constructed - will attract new 
activities) - has played a major role in the political debate on subsidies for transport for the 'mobility deprived' in remote areas. In recent years however, we observe a drastic change in the policy views on the 'obligatory' provisions of financial support that would ensure public service delivery to remote areas. First, in the phase of economic recession, public budgets are often by far insufficient to cover the related costs. Secondly, in the period of deregulation, decentralization and privatisation, commercial arguments have strongly come to the fore. This means that economic feasibility has become a major motive for sustaining transport connections to rural and peripheral areas. The above development has had far reaching implications for the morphology, the service level and the competitiveness of different networks. This applies to rail and bus services, to ferry systems, to road networks and to the aviation sector. This means that the connectivity of remote areas may become a problematic issue in the future. Despite European initiatives to plan for Trans-European Networks (TENs), there is a real threat that remote areas may again suffer from 'missing links'.

In the third place, there is a major more recent policy concern on the question whether transport will be devastating for environmentally sustainable development. Our mobile society fulfils many socio-economic needs, but calls at the same time also for social and political change in order to attain sustainable mobility. Both passenger and goods transport have rapidly increased in the past years, and for the time being there is no reason to expect a change in this trend. Some European scenarios forecast even a doubling of transport in one generation. This development provokes intriguing questions on the external (social) costs of transport, such as congestion, pollution and safety issues. Apart from local problems such as congestion or noise, the global environmental implications of transport are increasingly becoming a source of major concern. Although transport is responsible for a variety of greenhouse gas emissions, in recent years the attention has in particular focused on $\mathrm{CO}_{2}$ emissions. Despite many policy intentions, it seems to be very hard to curb the current emission trends. If one takes into consideration the expected economic growth in various Second and Third World countries, the future does not offer a very optimistic picture. The background of the externality problem of transport is caused by the fact that transport has 
low private costs accompanied by unpriced or underpriced external social costs. This has caused a transport-intensive life style and land-use in all countries, regions and cities.

The above observation that transport affects local and global environments in many ways can be illustrated by the following figures. For a number of pollutants, the transport sector is the most important contributor to environmental externalities. Within member countries of the Organization for Economic Co-operation and Development, about $60 \%$ of the $\mathrm{NO}_{\mathrm{x}}$ emissions, $80 \%$ of the $\mathrm{CO}$ emissions, $50 \%$ of the hydrocarbon emissions, $25 \%$ of the $\mathrm{CO}_{2}$ emissions, and $50 \%$ of the lead emissions (virtually $100 \%$ in urban areas) originate from transport activities. Safety and noise are also often mentioned as important environmental external costs of transport.

Notwithstanding the central role that transport plays in modern societies, it is increasingly recognized that current and predicted trends in personal mobility and freight transport, on local, regional and global levels, pose severe threats to the environment, and more stringent regulations of transport seem inevitable if policy goals related to global environmental sustainability are to be pursued. The European Union's most recent 'Green Paper' on transport leaves little ambiguity in this respect when stating that "...given the severity of the problems, action cannot be put off [...and...] adjusting the structure of existing tax systems by bringing charges closer to the point of use is likely to generate significant benefits" (EC, 1995). Indeed, economic instruments, advocated since the 1920s by Pigou as an efficient means of regulating transport externalities, now appear to have gained momentum also outside the academic world. It is interesting to observe that in recent years, many proposals have been made to favour environmental-benign transport systems and behaviour, ranging from road pricing, technological advances, technical standards, compact city design, land-use policy etc., but the results thus far have not yet been impressive. Although standard economic concepts are clear in that the user and the polluter should pay the full costs of travel (including all externalities), there are many problems with the implementation of such concepts; public acceptability is low and international agreements are difficult to reach.

The need for sustainable mobility and alternative land use policies has recently been recognized in the European Union. However, the foreseen massive investment in the 
transport and communications networks, particularly on a regional and international basis, is likely to increase journey lengths, the level of mobility and the volumes of freight flows. These outcomes are inconsistent with the objectives put forward by the European Union and its member states. And hence, there is a conflict between socio-economic needs and sustainable mobility needs.

Against these backgrounds, it is conceivable that the present European freight flow development is a source of much policy concern, not only from the viewpoint of efficient operations but also from the viewpoint of geographical equity and environmental sustainability. In this context, it is noteworthy that the European transport network is subdivided by the Alpine chain which causes a major fragmentation in the European transport and trade system. Futhermore, the Alpine countries (Austria, Switzerland) have also developed specific transport policy initiatives that serve to discourage road transport and to stimulate a shift to rail. Thus, modal split and route choice are two major features of current European transport policy options. The present paper focuses in particular on Transalpine freight traffic in Europe. It aims to assess the current flows by using proper spatial models on an interregional basis (based on logit analysis and neural network analysis), as well as to assess the expected consequences of new transport and environmental scenarios for European freight transport (e.g., a system of eco-taxes on freight transport). We will first offer a background sketch of recent transport developments around the Alpine chain in Section 2.

\section{SETTING THE SCENE}

A significant part of European freight transport is in North-South direction, given also the location of mainports in Northern and Western Europe. It is clear that Italy plays a prominent role in these transport flows. Given the strict link between Italy and the Alpine chain, which plays in a way the role of a gateway between South-Western Europe and Central/Northern Europe, some figures concerning the trade relationships in this framework will be presented. 
In 1993, the trade between Italy and the rest of the world was 345 million tons (hereinafter abbreviated as Mt). Figures 1 and 2 show that the importance of Europe as a whole increased considerably, accounting for over $72 \%$ of the value of imported goods and over $68 \%$ of that of exported goods. According to figures supplied by the Ministry of Transport, in $19936.8 \%$ of all goods in transit between Italy and other countries were transported by rail, $22.4 \%$ by road, $63.2 \%$ by sea and $7.6 \%$ by other means. The largest volume of goods was thus transported by sea, followed by road and then rail. However, if the value of the goods traded is taken into consideration, road transport is very much to the fore. The number of tons transported by road and/or rail was 101 bn in 1993, that is, $29.2 \%$ of the total goods transported. Their value, however, amounted to roughly $66.8 \%$ of that of international trade.

International road/rail transport in Italy, which means mainly intra-European trade, is divided into a volume of $60 \%$ imports and $40 \%$ exports. Road transport was more wellbalanced, with $38.9 \mathrm{Mt}$ entering Italy and $38.4 \mathrm{Mt}$ exiting (see Table 1). A considerable imbalance is evident from the following data: $66.3 \%$ of imports used road transport, while only $33.7 \%$ used rail. On the other hand, only $8.8 \%$ of all exports were transported by rail, while $91.2 \%$ of the total tonnage was exported by road transport. The latter as a whole accounted for $76.6 \%$ compared to $23.4 \%$ for rail.

These data clearly point at the crucial importance of the role played by Alpine routes in Italian international trade (in 1993 66.8\% of Italian trade value was oriented towards Europe) and also show the tendency towards the use of road transport, especially as far as export traffic is concerned.

\section{Figure 1 and 2 about here}

Table 1 about here

The increase in commodity transport in Europe is favourable from an economic perspective, but environmentally devastating. Therefore, several recent policy initiatives have been undertaken by the European Community. The major policy direction in many reports, issued by the various bodies of the EU, is based on three main principles: 
- the promotion of a fair division of the market for environmentally benign means of transport so as to favour the railway network, inter alia through active policies aimed at combined transportation and flanking policies limiting the growth of the road transport sector;

- the development of new transport systems and logistic technologies encouraging the maximum exploitation of existing infrastructures, above all as far as environmental protection is concerned;

- the implementation of the principle that users should be requested to cover the actual costs of transport, whether these refer to external issues or to the infrastructures.

The most important innovation regards the idea that a reversal of the present road/rail market share is needed. Rail is shown as the mean of transport that is most able to offer adequate capacity so as to cover any future demand. Other points very closely linked to environmental issues, viz. a tolerable level of development and the quality of life, have also played a decisive role in the decision-making policies of the EU. The most proper way to induce the necessary changes has appeared to be the choice of combined transport for freight in Europe.

The thorny question concerns now the design of a European infrastructure required to back up a modern transport system, and in particular, the creation of a logistic network consisting of hubs, interports, goods distribution centres, rail, port and airport terminals that are well integrated and linked to a telecommunications and computer network, hopefully at a European level. For freight carriers and the State railways, integrating into a European system means assuming the role of integrated logistic operators covering the whole European network and also implies working for the common good rather that in direct competition.

Problems concerning road transport appear to be particularly serious, considering that the sector, well-protected and in a favourable position in the past, must now change radically in order to conform to the free market imposed by the implementation of a domestic European market. In the future, this sector will be composed of a relatively small number of companies (operators), all of which will however, have made large investments of capital, employ highly skilled labour and offer a wide variety of products and services. 
Planning of the European transport network must therefore be based on the quality and quantity of physical infrastructures. Such changes must include strategic factors which are nowadays just as important or perhaps even more important (Uniontrasporti, 1995). These factors are specified by the various European Community directives and refer to the development of co-operative networks, the coverage of actual transport costs by the users, the integration of information exchanges, the acceptance of the principle of a tolerable level of development, and the inclusion of private capital in the implementation of the entire network project. It goes without saying that the development of effective policies presupposes sufficient knowledge on European freight flows and on their sensitivity to transport costs and distance frictions. This is the subject of the next section.

\section{EMPIRICAL APPLICATIONS: POLICY SCENARIO EXPERIMENTS BY MEANS OF LOGIT MODELS AND NEURAL NETWORKS}

\subsection{Introduction}

The final aim of the present paper is to investigate freight flow patterns in the Transalpine area from a multiregional perspective, by looking into the modal choice for these goods mainly from the viewpoint of time/freight costs. In this paper, two competing models, viz. a discrete choice model and a neural network model, wil be employed to map out the spatial flow patterns in an explanatory context. This offers also a possibility to compare the relative performance of those models. By considering that the Alpine chain 'ideally' divides Europe from Italy and Greece, a selection of Italian/Greek regions will be used to test the predictive power of the models concerned (inflows from Europe to Italy/Greece; outflows from Italy/Greece to Europe). Next, a sensitivity analysis will be carried out in order to investigate the expected consequences of a rise in time, due to, e.g., congestion factors as well as of a rise in transport costs, e.g. as a consequence of a European environmental tax on freight costs.

In the previous sections we outlined how, after the completion of the European market and with the widening of Europe towards easterly direction, mobility in general has drastically increased in Europe. In particular, cross-border transport has been at a rising 
edge with annual growth rates exceeding 10 percent, a process reinforced by the current globalisation trends. The integration of former segmented markets -and the related liberalisation in the European space- has led to drastic changes in both goods and passenger transport.

European networks and especially the Transalpine chains, are seen as the backbone of integration forces, while changes in the morphology of the networks are expected to generate system-wide impacts. Clearly, the emphasis on the potential of these networks for competitiveness and cohesion provokes various questions on the relative efficiency and substitutability of the different modes of this network. This issue is particularly important, as the competition between different modes and the social acceptability of modal choices are not only determined by the direct operational costs, but also by environmental externalities.

As a result, there is an increasing interest in the issue of intermodal competition and complementarity. For surface transport in Europe, especially the competitive position of rail vis-à-vis road is at stake. This holds increasingly also for commodity transport. It needs to be added however, that the analysis of freight transport in Europe is fraught with many difficulties, as freight is not a homogeneous commodity, but is composed of an extremely diversified set of goods with specific haulage requirements and logistic needs. This means that a commodity sector approach is necessary to analyse in depth implications of changes in network configurations. This approach will also be adopted in the present paper.

\subsection{The Freight Flow Models Used}

The present section aims to analyse interregional freight transport movements in Europe (108 regions) with particular reference to the Transalpine sector, as well as to forecast spatio-temporal flow patterns on the basis of new transport economic scenarios. For this purpose, a modal split analysis will be carried out by means of two statistical models, namely the logit model and the neural network model. 


\subsubsection{The logit approach}

A widely adopted approach for modal split analysis is the logit model (see e.g. BenAkiva and Lerman, 1985). Recent experiments using logit models / spatial interaction models in order to map out the freight transport in Europe have been carried out by Tavasszy(1996), who showed the suitability of logit models also for the goods transport sector (where data are more 'fuzzy' and incomplete compared to the passenger sector). Logit models are discrete choice models, which are used for modeling a choice from a set of mutually exclusive and exhaustive alternatives. It is assumed that the decision-maker chooses the alternative with the highest utility among the set of alternatives. The utility of an alternative is determined by a utility function, which consists of independent attributes of the alternative concerned and the relevant parameters.

Since in our case two discrete choices - rail (t) and road (c) - will be considered, a binary logit model is adopted by considering, as attributes, the variables 'time' and 'cost' between the 108 zones.

\subsubsection{The neural network approach}

Neural network (NN) analysis has in recent years become a popular analysis tool. NNs replicates human brain functions and are thus considered as 'intelligent', since they learn and generalize by examples (see e.g. Reggiani et al., 1997a). NNs have been widely applied to the area of transport engineering, in particular in relation to traffic control problems and accidents (see Himanen et al., 1997). However, only a few experiments exists in the field of transport economics or transport route / mode / destination choice (see e.g. Nijkamp et al., 1996a,b and Schintler and Olurotimi, 1997). Our experiments aim to explore also this novel research direction.

Following the majority of applications on NNs, in this study a two-layer feedforward, totally connected NN will be used in order to analyse the freight transport modal split problem. The methodological structure of the main steps related to the application of a feedforward NN is described in Reggiani and Tritapepe (1997). Concisely, it consists of three stages: a) definition of network architecture; b) learning phase; c) forecasting phase. It is thus first necessary to define the right architecture of the network, i.e. the number of units 
on the relevant levels. Usually, the input and output units depend on the number of input and output variables which define the problem (see Figure 3). In our application one possible NN architecture contains 4 input units which correspond to the attributes time and cost related to each transport mode (rail and road) and one output unit corresponding to the probability of choosing one mode ${ }^{1}$ (e.g., the rail mode). In the past years we have witnessed an increasing acceptance of $\mathrm{NN}$ models in social science research, including transportation science. Section 3.3 will offer empirical results obtained by applying an NN model to European freight flow data with particular attention to sensitivity/forecast analyses - based on policy scenarios - concerning the Transalpine area.

\subsection{Empirical Application}

In this section the sensitivity analysis resulting from experiments with the logit and the neural network approach will be presented and discussed.

\subsubsection{The Data}

The data set $^{2}$ contains the freight flows and the attributes related to each link between 108 European regions $^{3}$ for the year 1986. The attributes considered are 'time' and 'cost' between each link (ij) with reference to each transport mode. In particular, each observation of the data set pertains to variables related to each link (ij). Furthermore, the flow distribution in the matrices concerned refers to one particular kind of goods, viz. food.

Since 108 areas have been considered, the data set should ideally contain 11664 observations (according to the previous remarks on our observations). However, our data set contains finally 4409 observations because of the following considerations (by analysing the data set):

- the intra-area freight flows are zero;

\footnotetext{
${ }^{1}$ The choice probability of the other mode is just the complement.

${ }^{2}$ The data set has been kindly provided by NEA Transport Research and Training, Rijswijk.

${ }^{3}$ The map and list of regions is displayed in Reggianiet al. (1997b).
} 
- for each link, only the transport movements towards one direction $\mathrm{i} \rightarrow \mathrm{j}$ have been considered;

- only the links where the flows and the attributes (of both road and rail) are different from zero have been considered (i.e., empty cells are excluded).

The data set has been randomly subdivided into three sub-sets:

- a training set containing 2992 observations, i.e. about $68 \%$ of the data-set;

- a cross-validation set containing 447 observations, i.e. about $10 \%$ of the data-set;

- a test set containing 970 observations, i.e. about $22 \%$ of the data-set.

\subsubsection{The spatial forecasting: comparison of the logit and neural network approach}

In this subsection, the spatial forecasting performance of the two alternative approaches adopted will be compared and evaluated, on the basis of the calibration/learning procedure carried out in Reggiani et al.(1997b).

By using the test set, which was not used for the calibration procedure, in our procedure both the binary logit and the neural network model have been employed to predict the freight flows for link (ij). This performance has been evaluated using the statistical indicator ARV (Average Relative Variance) which reads as follows:

$$
A R V=\frac{\sum(y-\bar{y})^{2}}{\sum(y-\bar{y})^{2}}
$$

where $y=$ the observed transport flow using road, $\hat{y}=$ the transport flow using road, as predicted by the adopted model and $\bar{y}=$ the average of the observed transport flow using road (see Fischer and Gopal, 1994).

\section{Table 2. Comparison of Logit and NN performance}

\begin{tabular}{|l|c|}
\hline & ARV \\
\hline NN & 0.176 \\
Logit & 0.185 \\
\hline
\end{tabular}


According to the above ARV indicator, the NN approach for forecasting spatial flows performs overall slightly better than the logit approach (see Table 2). An extrapolation of the 'test set' results with reference to Italy and Greece (inflows to Europe/outflows from Europe) is displayed in Table 3 and 4 (see next section).

\subsubsection{Policy scenario experiments by means of logit and neural network analyses}

As mentioned above, freight transport causes high social costs, which might be charged to the transportation sector. We will now investigate the consequences of varying the transportation time/costs for freight flows. A sensitivity analysis of the previous results based on some economic scenarios will now be carried out in this section by using again both the binary logit model and the NN model. Two economic scenarios will be used; they will concisely be discussed here. Later on, we will present the results related to the sensitivity analysis for the logit and the neural network approach.

At present, because of severe problems on the road transport network (for example, congestion), governments are trying to reduce the road usage by imposing policy measures that serve to increase the cost of road usage (see Verhoef, 1996). An example of a Pigouvian policy for coping with environmental externalities is the recently increased tax on fuel in the Netherlands. In so doing, the usage of the road transport network is made less attractive than other transport networks. In the light of these recent developments, two scenarios have been developed and considered for an sensitivity analysis; these are based on the observations in the test set. In Scenario 1 we assume an increase in transportation time for congestion problems around 10\%. In Scenario 2 we assume that a uniform European tax policy for freight transport is also adopted and that the cost attribute related to the road mode is increased by $10 \%$ for all links (ij) (in addition to the previous increase of time).

The conditional predictions for the regions under analysis are presented in Tables 3 and 4 for the binary logit and the neural network model, respectively. The relative prediction error is defined as the difference between the predicted flow and the real flow as a percentage of the real flow. These tables indicate that the binary logit model is relatively more sensitive to changes in the time/cost attribute than the NN model. 
It is interesting to note that in the neural network case, and particularly in the case of inflows from Europe to Italy and Greece, the model shows -in the mean value- some increase of flows, despite the cost/time increase. This result may be plausible by taking into account the increasing amount of interaction among regional economies. It would certainly be relevant to compare these results with more updated data in order to better evaluate the 'forecasting' analysis of the two models, since we have used -as a starting point- a test set related to the year 1986.

However, the above results may be considered valid, in the absence of updated data that would be able to test our hypothesis of a $10 \%$ increase in the cost/time, given the good performance of the calibration / test phase (see Table 2). Moreover, these results may offer a 'range of values' to policy actors aiming to evaluate the impact of cost changes on flows, given the intrinsic limits of both adopted models.

On the one hand, the large amount of data at an aggregate level, hampers a behavioural perspective inherent in logit models. On the other hand, the type of architecture adopted in NN models seems critical for the validity of the results. Consequently, the results of our model may be used as a benchmark for the results of other models, by offering a more 'flexible' range of output results to policy actors.

\section{Tables 3 and 4 about here}

\section{CONCLUDING REMARKS}

The first part of the paper aimed to highlight the relevant role of the Alpine chain in the framework of existing scenarios and forecasts. It emerged that a 'global' policy perspective should take into account the potential and role of Transalpine freight transport, particularly with reference to the major four passes in the Alps.

The second part of the present paper has been empirically oriented, aiming to depict transport flows of commodities in an interregional European setting with reference to the Alpine crossing area. Based on an extensive (NEA) data set, various estimates of the 
impacts of time/costs on transport movements have been made. The test results show that both the logit and the NN approach are giving fairly favourable results. In general, NN models seem to perform slightly better. After this exploratory comparative study of two modelling approaches, it is certainly opportune to investigate more thoroughly the differences in background of these two research paradigms. It is well known that the logit model is a particular spatial interaction model that has its roots in social behaviour of actors, however with intrinsic limitations stemming from certain properties, like the well known IIA (Independence from Irrelevant Alternatives) assumption. The NN model is based on similarily of learning experiments and has certainly a behavioural adjustment potential, but is less easily interpretable from social science motives, even though recent results show a compatibility between feedforward NNs and binary logit models (see Schintler and Olurotimi, 1997), feedforward NNs and spatial interaction models (see Fischer and Gopal, 1994) and feedforward NNs and logistic regression models (see Schumacher et al., 1996). The emerging results reinforce the predictive ability of this parallel approach (logit and $\mathrm{NN}$ ) by showing the possibility of offering a range of forecasts - for the Alpine area - under alternative policy scenarios. 


\section{ACKNOWLEDGMENTS}

The first author gratefully acknowledges the Italian CNR Project PFT2 $\mathrm{n}^{\circ}$ 96.00098.PF74 as well as the MPI project 40\%. Lucia Nobilio is also gratefully acknowledged for the software elaboration concerning Section 3. 


\section{REFERENCES}

Ben-Akiva, M. and S. R. Lerman (1985). Discrete Choice Analysis: Theory and Application to Travel Demand, MIT Press, Cambridge, Massachusetts.

Fischer, M. M. and S. Gopal (1994). Artificial Neural Networks: A New Approach to Modelling Inter-regional Telecommunication Flows, Journal of Regional Science, 34, 503-527.

Himanen, V., P. Nijkamp and A. Reggiani (eds.) (1997). Neural Networks in Transport, Avebury, Aldershot (forthcoming).

Ministero dei Trasporti (1995). Conto Nazionale dei Transporti, Istituto Poligrafico e Zecca dello Stato, Roma.

Nijkamp, P., A. Reggiani and T. Tritapepe (1996). Modelling Inter-Urban Transport Flows in Italy: A Comparison between Neural Network Approach and Logit Analysis, Transportation Research C, 4, 323-338.

Nijkamp, P., A. Reggiani and T. Tritapepe (1997). Spatial Choice Behaviour: Logit Models and Neural Network Analysis, The Annals of Regional Science (forthcoming).

Reggiani, A. and T. Tritapepe (1997). Neural Networks and Logit Models to Commuters' Mobility in the Metropolitan Area of Milan. In: Neural Networks in Transport (V. Himanen, P. Nijkamp and A. Reggiani Eds.), Avebury, Aldershot (forthcoming).

Reggiani, A., R. Romanelli, T. Tritapepe and P.Nijkamp (1997a). Neural Networks: An Overview and Applications in the Space Economy. In: Neural Networks in Transport (V. Himanen, P. Nijkamp and A. Reggiani Eds.), Avebury, Aldershot (forthcoming).

Reggiani, A., P. Nijkamp and W.-F. Tsang (1997b). European Freight Transport Analysis Using Neural Networks and Logit Models. In: Accessibility, Trade and Locational Behaviour (A. Reggiani Ed.), Avebury, Aldershot (forthcoming).

Schintler, L. A. and O. Olurotimi (1997). Neural Networks as Adaptive Logit Models. In: Neural Networks in Transport (V. Himanen, P. Nijkamp and A. Reggiani Eds.), Avebury, Aldershot (forthcoming).

Schumacher, M., R. Roßner and W. Vach (1996). Neural Networks and Logistic Regression, Computational Statistics \& Data Analysis, 21, 661-682. 
Tavasszy, L. A. (1996). Modelling European Freight Transport Flows, Ph.D. Thesis, Delft University of Technology, Delft.

Uniontrasporti (1995). Il trasporto attraverso le Alpi, Uniontrasporti, Milano.

Verhoef, E. T. (1996). The Economics of Regulating Road Transport, Edward Elgar, Aldershot. 
Table 1 Trade between Italy and the Rest of Europe via the Various Transport Modes (1993)

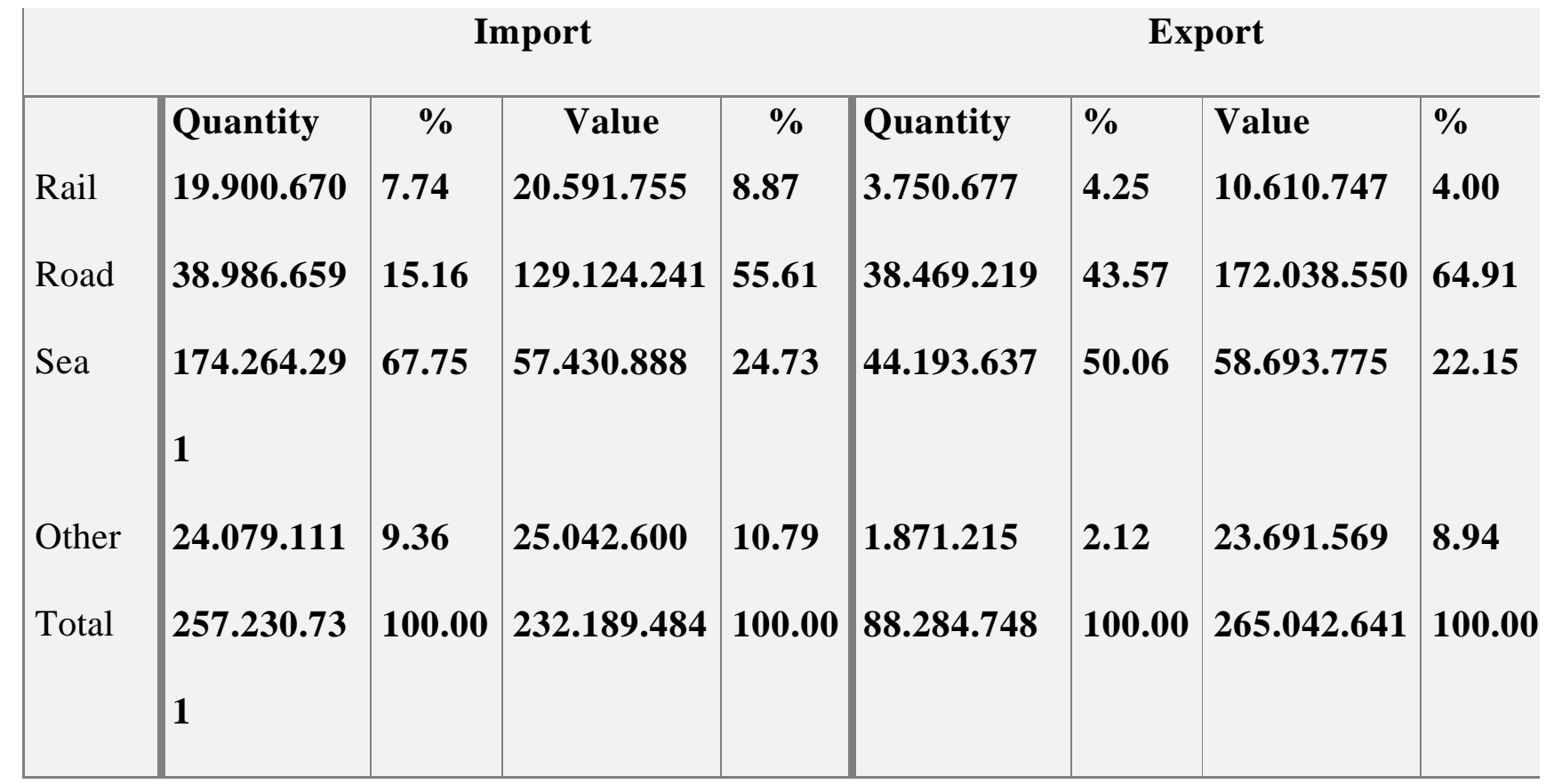

Source: Ministero dei Trasporti (1995) 
Table 3: Outflows from Europe ${ }^{\bullet}$ to Italy/Greece (mode transport: road; good category: food; year: 1986)

\begin{tabular}{|c|c|c|c|c|c|c|c|c|c|c|c|c|c|}
\hline \multirow[t]{2}{*}{ REGIONS } & \multirow[t]{2}{*}{$\begin{array}{l}\text { Real } \\
\text { Flows }\end{array}$} & \multicolumn{2}{|c|}{ Estimated flows } & \multicolumn{2}{|c|}{$\begin{array}{c}\text { Scenario 1 } \\
(\text { time }+10 \%)\end{array}$} & \multicolumn{2}{|c|}{$\begin{array}{c}\text { Scenario } 2 \\
((\text { time/cost })+ \\
10 \%)\end{array}$} & \multicolumn{2}{|c|}{$\begin{array}{l}\text { Estimated flows } \\
\text { rel. pred. err. }\end{array}$} & \multicolumn{2}{|c|}{$\begin{array}{c}\text { Scenario } 1 \\
\text { rel. pred. err. }\end{array}$} & \multicolumn{2}{|c|}{$\begin{array}{c}\text { Scenario } 2 \\
\text { rel. pred. err. }\end{array}$} \\
\hline & & LOGIT & $\mathbf{N N}$ & LOGIT & $\mathbf{N N}$ & LOGIT & $\mathbf{N N}$ & $\operatorname{Logit}(\%)$ & $\mathbf{N N}(\%)$ & Logit(\%) & NN(\%) & Logit $(\%)$ & $\begin{array}{c}\mathbf{N N}(\%) \\
)\end{array}$ \\
\hline Thessaloniki & 44380 & 38636 & 43297 & 22564 & 42904 & 29176 & 43115 & -12.94 & -2.44 & -49.16 & -3.33 & -34.26 & -2.85 \\
\hline \begin{tabular}{|l|} 
Athens \\
\end{tabular} & 52047 & 43557 & 51038 & 16050 & 50565 & 39341 & 50693 & -16.31 & -1.94 & -69.16 & -2.85 & -24.41 & -2.60 \\
\hline Patras & 53626 & 46130 & 52145 & 25265 & 52340 & 35481 & 52603 & -13.98 & -2.76 & -52.89 & -2.40 & -33.84 & -1.91 \\
\hline Heraklion & 56930 & 53420 & 56916 & 50317 & 57730 & 30332 & 57824 & -6.17 & -0.02 & -11.62 & 1.41 & -46.72 & 1.57 \\
\hline Turin & 259075 & 379966 & 398615 & 343890 & 401170 & 220704 & 401352 & 46.66 & 53.86 & 32.74 & 54.85 & -14.81 & 54.92 \\
\hline Milan & 414190 & 350049 & 432237 & 386103 & 432723 & 208729 & 432999 & -15.49 & 4.36 & -6.78 & 4.47 & -49.61 & 4.54 \\
\hline \begin{tabular}{|l} 
Venice \\
\end{tabular} & 53795 & 40932 & 56748 & 47947 & 56775 & 26790 & 56851 & -23.91 & 5.49 & -10.87 & 5.54 & -50.20 & 5.68 \\
\hline Bologna & 365183 & 355578 & 377438 & 365225 & 378716 & 192796 & 379190 & -2.63 & 3.36 & 0.01 & 3.71 & -47.21 & 3.84 \\
\hline Florence & 178632 & 157254 & 185540 & 164387 & 181798 & 101032 & 182357 & -11.97 & 3.87 & -7.97 & 1.77 & -43.44 & 2.09 \\
\hline \begin{tabular}{|l|} 
Ancona \\
\end{tabular} & 43653 & 42143 & 43540 & 42401 & 43617 & 22771 & 43574 & -3.46 & -0.26 & -2.87 & -0.08 & -47.84 & -0.18 \\
\hline Pescara & 119774 & 113282 & 115746 & 107433 & 116100 & 64002 & 116021 & -5.42 & -3.36 & -10.30 & -3.07 & -46.56 & -3.13 \\
\hline Rome & 35705 & 31264 & 34076 & 30840 & 34466 & 18261 & 34464 & -12.44 & -4.56 & -13.63 & -3.47 & -48.86 & -3.48 \\
\hline \begin{tabular}{|l|} 
Naples \\
\end{tabular} & 183553 & 188948 & 194825 & 140320 & 197702 & 122312 & 197946 & 2.94 & 6.14 & -23.55 & 7.71 & -33.36 & 7.84 \\
\hline Bari & 105824 & 93432 & 99806 & 99633 & 101972 & 52125 & 102277 & -11.71 & -5.69 & -5.85 & -3.64 & -50.74 & -3.35 \\
\hline Reggio C. & 29960 & 29558 & 28841 & 21101 & 28566 & 20258 & 28608 & -1.34 & -3.73 & -29.57 & -4.65 & -32.38 & -4.51 \\
\hline Palermo & 126464 & 114747 & 124608 & 90232 & 126808 & 75681 & 127036 & -9.27 & -1.47 & -28.65 & 0.27 & -40.16 & 0.45 \\
\hline \begin{tabular}{|l|} 
Cagliari \\
\end{tabular} & 64435 & 57372 & 64633 & 64478 & 64336 & 31155 & 64503 & -10.96 & 0.31 & 0.07 & -0.15 & -51.65 & 0.11 \\
\hline M* & & & & & & & & -6.38 & 3.01 & $\begin{array}{c}-17.06 \\
\end{array}$ & 3.30 & -40.94 & 3.47 \\
\hline MA** & & & & & & & & 12.21 & 6.10 & 20.92 & 6.08 & 40.94 & 6.06 \\
\hline
\end{tabular}

Notes to table 3:

- Spain and Portugal have been not considered.

* $\mathrm{M}=$ mean value of the variations from the real data.

** MA $=$ mean value of the absolute variations from the real data. 
Table 4: Inflows to Europe ${ }^{\bullet}$ from Italy/Greece (mode transport: road; good category: food; year: 1986)

\begin{tabular}{|c|c|c|c|c|c|c|c|c|c|c|c|c|c|}
\hline \multirow[t]{2}{*}{ REGIONS } & \multirow[t]{2}{*}{$\begin{array}{l}\text { Real } \\
\text { Flows }\end{array}$} & \multicolumn{2}{|c|}{ Estimated flows } & \multicolumn{2}{|c|}{$\begin{array}{c}\text { Scenario 1 } \\
(\text { time }+10 \%)\end{array}$} & \multicolumn{2}{|c|}{$\begin{array}{c}\text { Scenario } 2 \\
((\text { time/cost })+ \\
10 \%)\end{array}$} & \multicolumn{2}{|c|}{$\begin{array}{l}\text { Estimated flows } \\
\text { rel. pred. err. }\end{array}$} & \multicolumn{2}{|c|}{$\begin{array}{c}\text { Scenario } 1 \\
\text { rel. pred. err. }\end{array}$} & \multicolumn{2}{|c|}{$\begin{array}{c}\text { Scenario } 2 \\
\text { rel. pred. err. }\end{array}$} \\
\hline & & LOGIT & $\mathbf{N N}$ & LOGIT & $\mathbf{N N}$ & LOGIT & $\mathbf{N N}$ & Logit(\%) & $\mathbf{N N}(\%)$ & Logit(\%) & NN(\%) & Logit $(\%)$ & $\begin{array}{c}\mathbf{N N}(\%) \\
)\end{array}$ \\
\hline Thessaloniki & 19764 & 16122 & 19274 & 6649 & 19324 & 16283 & 19488 & -18.43 & -2.48 & -66.36 & -2.23 & -17.61 & -1.40 \\
\hline \begin{tabular}{|l|} 
Athens \\
\end{tabular} & 25965 & 29120 & 28287 & 6813 & 28431 & 26213 & 28501 & 12.15 & 8.94 & -73.76 & 9.50 & 0.96 & 9.77 \\
\hline Patras & 22569 & 13082 & 22478 & 8713 & 22101 & 16846 & 22155 & -42.04 & -0.40 & -61.39 & -2.07 & -25.36 & -1.83 \\
\hline Heraklion & 18622 & 17711 & 19104 & 12340 & 19055 & 12086 & 19052 & -4.89 & 2.59 & -33.73 & 2.33 & -35.10 & 2.31 \\
\hline Turin & 820281 & 724980 & 780102 & 774691 & 793751 & 400811 & 796122 & -11.62 & -4.90 & -5.56 & -3.23 & -51.14 & -2.95 \\
\hline Milan & 3980845 & 3137979 & 3835833 & 3880482 & 3874579 & 1808444 & 3887546 & -21.17 & -3.64 & -2.52 & -2.67 & -54.57 & -2.34 \\
\hline \begin{tabular}{|l|} 
Venice \\
\end{tabular} & 922574 & 648524 & 864446 & 886303 & 830692 & \begin{tabular}{|l|}
392430 \\
\end{tabular} & \begin{tabular}{|l|}
831592 \\
\end{tabular} & -29.70 & -6.30 & -3.93 & -9.96 & -57.46 & -9.86 \\
\hline Bologna & 7213650 & \begin{tabular}{|l|}
5821584 \\
\end{tabular} & 6442638 & 7057064 & 6247481 & 3258554 & 6257957 & -19.30 & $\begin{array}{l}-10.69 \\
\end{array}$ & -2.17 & -13.39 & -54.83 & -13.25 \\
\hline Florence & 1143048 & 1055770 & 1044481 & 1102063 & 1014918 & 559767 & 1011246 & -7.64 & -8.62 & -3.59 & -11.21 & -51.03 & -11.53 \\
\hline \begin{tabular}{|l|} 
Ancona \\
\end{tabular} & 1035352 & 992532 & 931062 & 991756 & 892805 & 518466 & 893153 & -4 & -10.07 & -4 & -13.77 & -49.92 & -13.73 \\
\hline \begin{tabular}{|l|} 
Pescara \\
\end{tabular} & 683626 & 628053 & 624495 & 642061 & 616435 & 339372 & 615614 & -8.13 & -8.65 & -6.08 & -9.83 & -50.36 & -9.95 \\
\hline Rome & 351976 & 313587 & 318727 & 329765 & 304467 & 172024 & 301735 & -10.91 & -9.45 & -6.31 & -13.50 & -51.13 & -14.27 \\
\hline Naples & 1258182 & \begin{tabular}{|l|}
1167890 \\
\end{tabular} & 1155432 & 1190396 & 1135565 & \begin{tabular}{|l|}
624124 \\
\end{tabular} & \begin{tabular}{|l|l}
1129908 \\
\end{tabular} & -7.18 & -8.17 & -5.39 & -9.75 & .39 & -10.20 \\
\hline Bari & 2442992 & 2086402 & \begin{tabular}{|l|}
2279118 \\
\end{tabular} & 2385679 & 2202194 & \begin{tabular}{|l|l|}
1120275 \\
\end{tabular} & 2186937 & -14.60 & -6.71 & -2.35 & -9.86 & -54.14 & -10.48 \\
\hline Reggio C. & 222407 & 211238 & 209597 & 205187 & 202594 & 113536 & 201097 & -5.02 & -5.76 & -7.74 & -8.91 & -48.95 & -9.58 \\
\hline Palermo & 703347 & 614024 & 668120 & 567622 & 646903 & 389092 & 645495 & -12.70 & -5.01 & -19.30 & -8.03 & -44.68 & -8.23 \\
\hline \begin{tabular}{|l|} 
Cagliari \\
\end{tabular} & 48357 & 48196 & 46894 & 48921 & 45347 & 24706 & 45661 & -0.33 & -3.03 & 1.17 & -6.22 & -48.91 & -5.58 \\
\hline M* & & & & & & & & -12.10 & -4.84 & -17.8 & -6.6 & -43.80 & -6.65 \\
\hline MA** & & & & & & & & 13.53 & 6.20 & 17.97 & 8.03 & 43.91 & 8.07 \\
\hline
\end{tabular}

Notes to table 4:

- Spain and Portugal have been not considered.

* $\mathrm{M}=$ mean value of the variations from the real data.

** MA $=$ mean value of the absolute variations from the real data. 


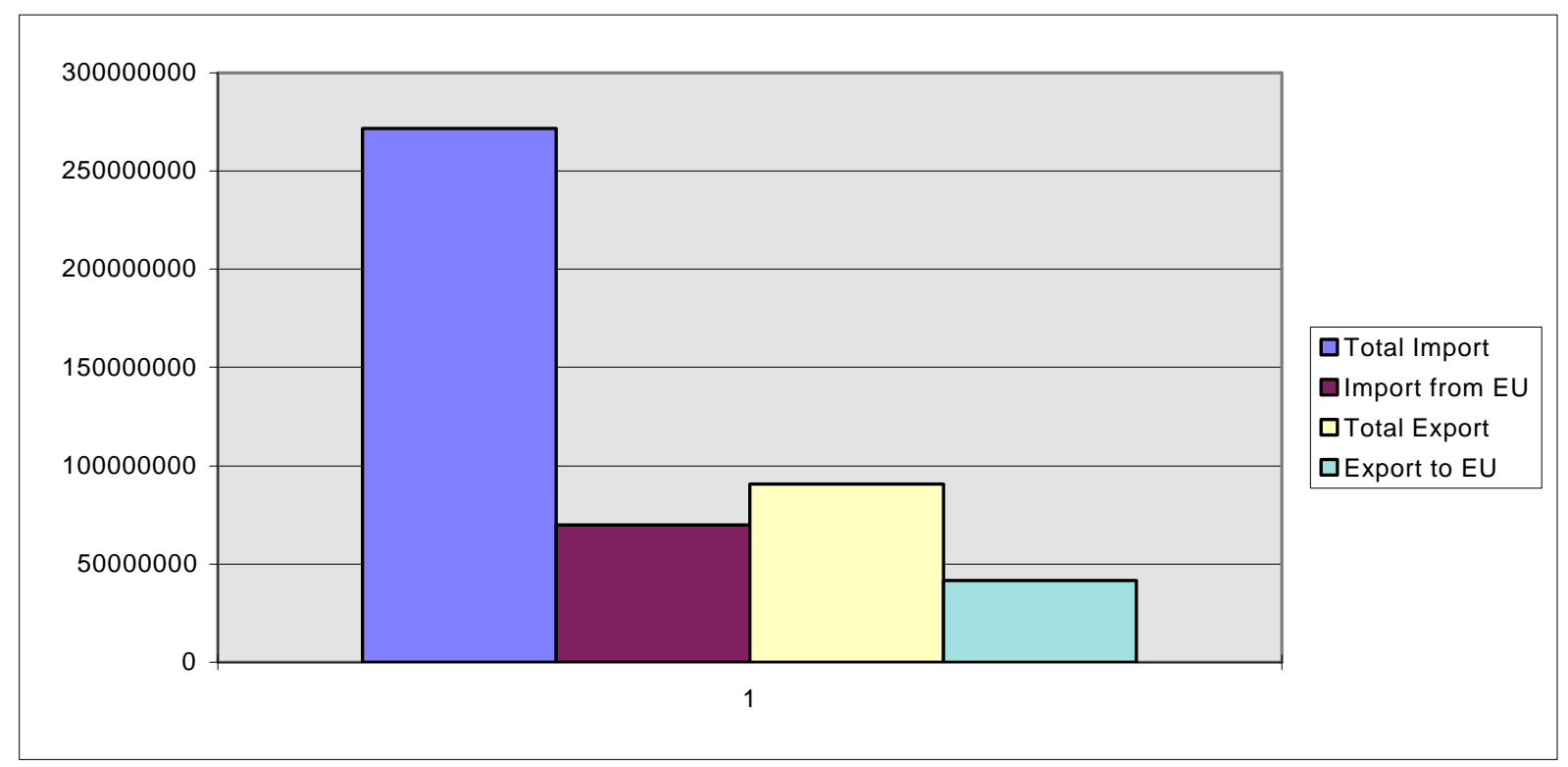

Figure 1 Quantity of Import/Export in Italy (year 1994)

$\mathrm{x}$-axis: Import/Export; y-axis: Tons

Source: Ministero dei Trasporti (1995)

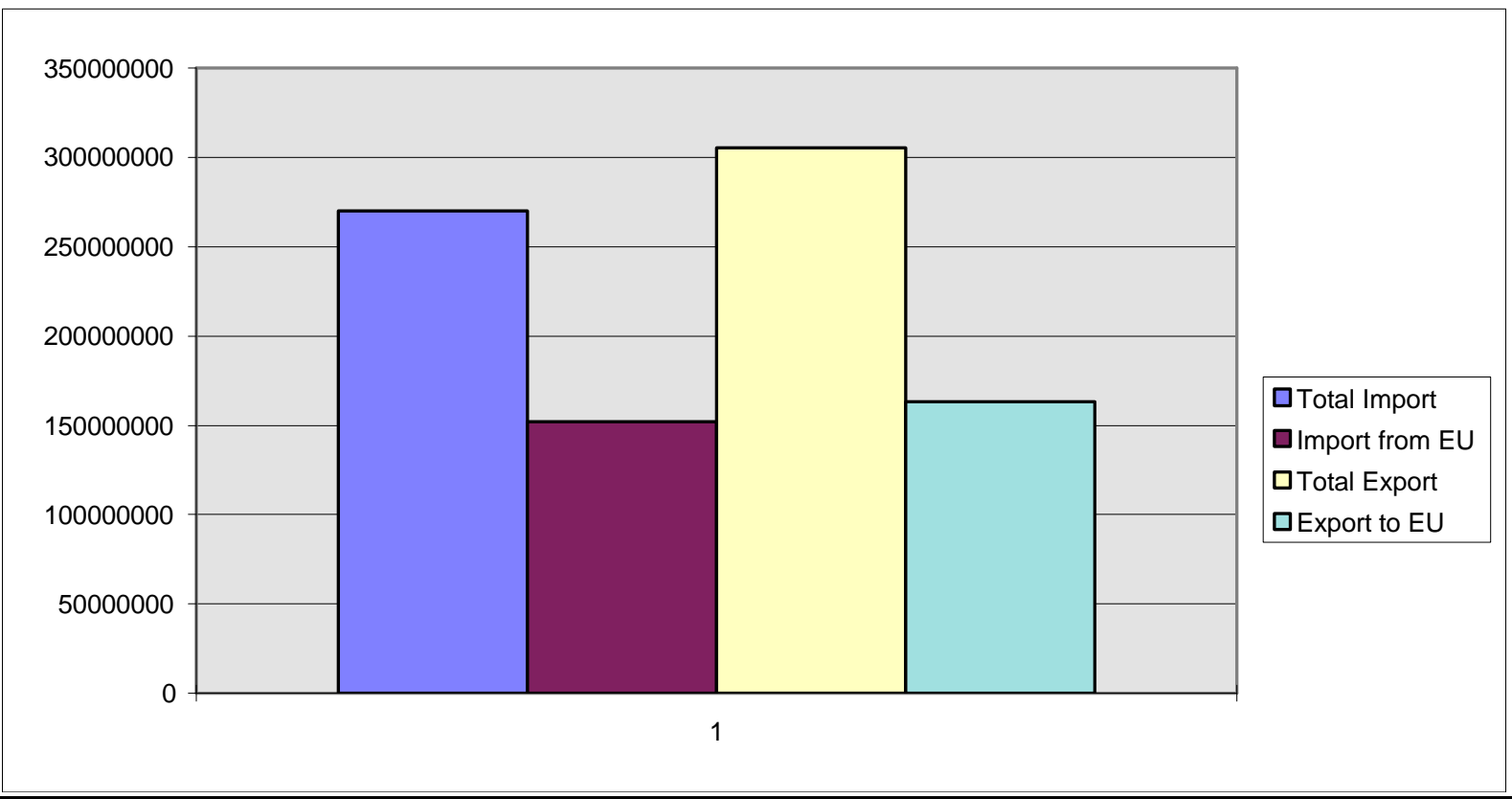

Figure 2 Value of Import/Export in Italy (year 1994); x-axis: Import/Export; y-axis: Thousands of Italian Lire Source: Ministero dei Trasporti (1995) 


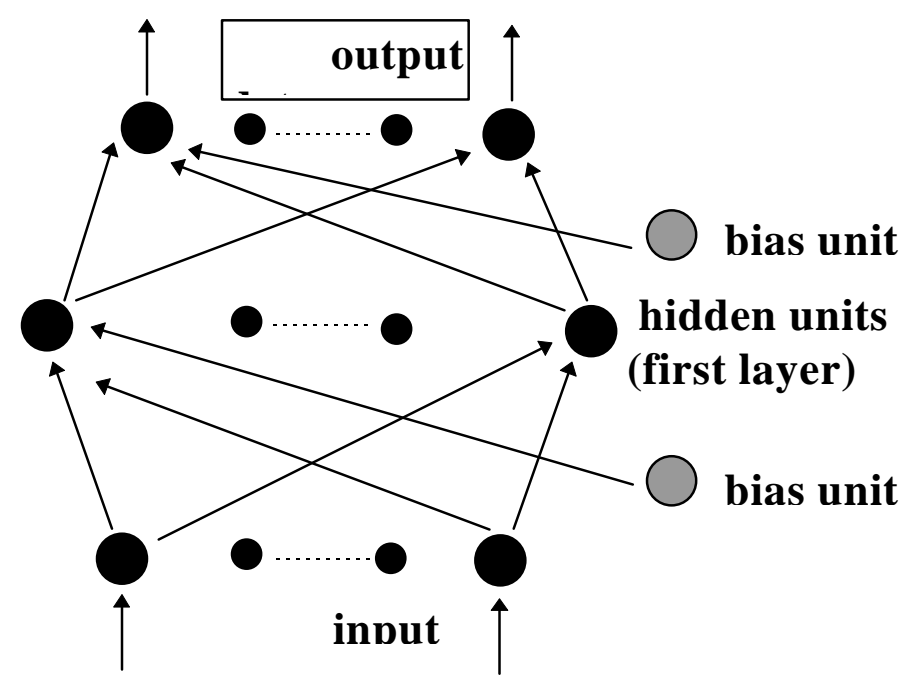

Figure 3 A feedforward neural network architecture 